Vol. 3, No. 2 | July - December 2020

\title{
Micro-Grid Stability Improvement Using Static Synchronous Compensator Assisted with Battery Energy Storage System
}

\author{
Saqif Imtiaz ${ }^{1}$, Muhammad Massab Khan ${ }^{1}$, Zubair Yamin², Muhammad \\ Siddique $^{1}$, Ashfaq Riaz ${ }^{1}$
}

\begin{abstract}
:
Integration of distributed generation (DG) with distribution network is essential for best utilization of renewable resources in better economics and clean environmental aspect. Micro-grid (MG) is an aggregation of electrical loads and DGs. Intermittencies of load variation has adverse effect on the voltage at the point of a common couple (PCC). It also prevents the restoring of MG power back to stable state, and voltage instability at PCC makes MG weak interconnection with distribution power grid1. In this article, placement of static synchronous compensator (STATCOM) Assisted with Battery energy storage system (BESS) at PCC scheme is developed. STATCOM assisted with battery energy storage system (BESS) provides instant real power and reactive power support for coupled MG with power grid to ensure voltage stability margin at PCC and it is effective in restoring power stability2,3. Proposed scheme is implemented on a test system which is simulated in MATLAB-SIMULINK. The obtained results verify the effectiveness of placing STATCOM assisted with BESS at PCC.
\end{abstract}

Keywords: Micro-grid (MG), Distributed power generation (DG), Load variation, Voltage stability margin, Point of common coupling (PCC), Static synchronous compensator (STATCOM), Battery energy storage system (BESS), Power support

\section{Introduction}

Nowadays, power demand is growing in exponential fashion across the globe. Power consumers expect continuous, reliable and efficient power from utilities. Conventional power plants run on fossil fuels, which are less convenient in economic and environmental aspects4. This is due to the rapid depletion of natural resources and carbon emissions. $\mathrm{CO} 2$ contributes greatly to global warming. For these reasons conventional resources are less preferable [1]. Modern research is more focused on finding efficient ways for power generation. This mainly includes exploitation of renewable energy resources (RERs). Throughout the world, great attention has given to these renewable resources for electric power generation purposes5 [2]. Especially Europe intends to switch its power sector from conventional to renewable resources completely [3]. For that purpose, they are focused on solar, wind, biogas, geothermal, wave energy, ocean thermal energy (OTEC) and biomass.

The concept of distribution generation (DG) system is used to integrate RERs in the power system 13. Renewable energy resources

\footnotetext{
${ }^{1}$ Department of Electrical Engineering, NFC IET. Multan, Pakistan

${ }^{2}$ Department of Electrical Engineering, NUST College of E\&ME. Rawalpindi, Pakistan Corresponding Author: zubbairyamin@gmail.com
}

$$
\text { SJET | ISSN: 2616-7069 | Vol. } 3 \text { | No. } 2 \text { | } 592020 \text { Sukkur IBA University }
$$


Saqif Imtiaz (et al.), Micro-Grid Stability Improvement Using Static Synchronous Compensator Assisted with Battery Energy Storage System

(pp. 59-72)

are integrated at distribution level to avoid

transmission network losses [4].

Independently operating solar, wind, micro

hydal, biomass, tidal units can be used as DGs

[5]. Micro-grid comprises DGs and local consumer load overcomes the deficiencies of DGs like randomness and intermittency [6]. It also links the entire DG network to the main power stream. However, this MG integration creates several operational challenges for the power system in both grids connected mode and islanded mode [7].

These days power utilities encounter voltage instability and lower power factor issues due to rapid increase in domestic and industrial loads worldwide6. The main target of utilities is to fulfill consumer demands reliably and efficiently. It also means that the consumer gets continuous supply of highquality power at economical rates. Previous research revealed that about $13 \%$ of the generated power is wasted in terms of power losses in a line7. Expansion of the distribution network requires supplementary complexity and proper maintenance of the power system8. Abnormality due to both high and low voltages always contributes in the deterioration of power instruments, therefore always voltage stability9 is required at the customer's end. Sudden load variation of heavy inductive loads in power system causes voltage drop, voltage instability, power losses and increase in power energy cost 10 . When reactive power lower voltage stability current value is increased to adjust the power supplied, so more consumed reactive power is the major reason for the voltage drop in distribution networks11 [8]-[10]. To mitigate losses and improve voltage profile different compensation devices are used such as capacitor banks, voltage regulators, on load tap changers (OLTCs) in widespread distribution networks. There is high energy demand on the distribution grid causes reduction in supply voltages from the grid to end-users12,13. Static VAR compensator (SVC) is a flexible ac transmission system (FACTS) device for voltage regulation to minimize power losses. SVC is a thyristor control reactor device that absorb/supply the

reactive power from/into the system13. The DGs are integrated with the distribution system to meet the energy demand and minimize voltage variations, which affects the performance of OLTCs and the switchedcapacitor of the system [11]. SVC and STATCOM is used for reactive power reserve management in IEEE 9 and IEEE 14 bus system14 [12].

The selection of suitable size and location for FACTs devices is a big issue that needs to be resolved. Different optimization techniques and search algorithms are used in finding out the best location and sizing of FACTS controllers. Optimizing algorithms like an artificial-bee colony, particle swarm optimization, novel-global harmony, search methodologies, and many other algorithms are widely used these days to solve the problem of acquiring the most candidate bus or line for placement of voltage controlling devices 15 [13], [14]. In [15], the authors used a line stability indicator to identify the weakest lines in the distribution network for voltage profile improvement and mitigate power losses using the FACTS controller and shunt capacitor. Review in [16], suggested that different techniques such as artificial-neural network, analytical, sensitivity-approaches, MetaHeuristic, combined Meta-Heuristic and sensitivity approaches are used to identify the optimum location and sizing of distribution static synchronous compensator (DSATCOM) for mitigating voltage deviations, reducing power loss and voltage stability of distribution system network16. The thyristor control circuit for SVC is proposed for power factor correction and voltage improvement at static and dynamic loads conditions. Results of the measured power factor and voltage from software and hardware were compared17 [17].

To reduce voltage oscillations and power losses, DGs and SVC are integrated into the distribution network in [18]. Revamp voltage stability indicator is deployed to investigate the weakest bus on the power system in the short computational-time. The designed methodology is implemented on a 14-bus system using etap software18. In [19], authors SJET | ISSN: 2616-7069 | Vol. 3 | No. 2 | @ 2020 Sukkur IBA University 
develop a global attainment topology to solve the problem of multi-objective optimization. Capacitor banks and SVCs are correlated with DGs in the distribution system to eliminate voltage variations and reducing real power losses. The maximum hosting capacity of the distribution system for renewable energy based distributed generators are discussed in [20]. Here a strategy based on the operation of robust on load tap changer and SVC is proposed, which considers uncertainties in both load consumption and power generation from DGs. It was tested and verified on the IEEE 33-bus distribution system19,20. In [21], authors developed Mix Integer Linear Program (MILP) to achieve the optimum location of static VAR compensators (SVCs) to maximize hosting-capacity of PV based DG. The objective of MILP is to maintain the voltage stability and invested cost on SVCs 21 . Voltage stabilization and reactive power flow of STATCOM in a microgrid are studied in [22]. A detailed analysis is carried out on control of reactive power flow in different scenarios to meet the grid requirements. Optimal sizing and placement of capacitors in the radial distribution system for enhancing voltage profile and reduction in power losses are addressed in [23]. This approach is carried out in two stages. In the first stage loss, sensitivity analysis is performed for the optimal location for capacitor and in the second stage, ant colony optimization algorithm is examined for optimum size and location of the capacitor in the distribution network while minimizing the cost and energy losses at the same time. Results from 34-bus and 85-bus radial distribution systems support the integrity of the proposed strategy 22 , in article [24], the authors used voltage stability index (VSI) for identification of the most critical bus on the distribution power network for the installation of distributed generation. Optimum DG size is selected by the genetic algorithm so that the power quality and voltage profile is improved. The proposed methodology is tested on IEEE 33 bus and IEEE 69 bus distribution system 23 .

In [25], voltage fluctuations in the output of a hybrid microgrid based on wind and solar energy are compensated by the utilization of STATCOM. In this way, the stable operating limits of this hybrid microgrid was increased. The PI controllers of the STATCOM were optimized by using bacteria foraging and genetic algorithms, thus achieving a better response in terms of voltage stability in the presence of the intermittent nature of windsolar hybrid microgrid. Results from the conventional PI controller and other suggested optimized algorithms in STATCOM were compared to demonstrate the efficiency of the proposed methodology25. A detailed comparison of SVC and STATCOM for transient voltage stability in DFIG based wind farm is presented in [26]. This research work proposed that STATCOM even with low capacity as compared to the SVC is more reliable and cost-effective. That's because it provides reactive power for voltage stability at much faster rates in contrast to the SVC. A novel model based on a voltage source converter with a battery energy storage system that provides reactive power support to the distribution system for voltage profile enhancement and load leveling is proposed in 24 [27]. Issues related to the integration of microgrid with the traditional grid for smooth operation in grid-connected mode is presented in [28]. Fluctuations in the load curve cause voltage instability at the point of the common couple. A stability management controller is designed and tested for stabilizing the voltages at the point of integration to overcome interconnection issues. This controller helped in securing the voltage at the interconnection25. This work on micro-grid stability improvement using STATCOM with assisted BESS is a new contribution in the existing literature by taking these factors simultaneously as;

- Voltage stability at point of integration

- Active power and reactive power management

- $\quad$ Restoring power stability of micro-grid ${ }^{1}$

This article deals with the problems of voltage instability at the point of common coupling (PCC) and power restoring of microgrid when it faces high intermittencies of load 
Saqif Imtiaz (et al.), Micro-Grid Stability Improvement Using Static Synchronous Compensator Assisted with Battery Energy Storage System

variation at PCC26. Classification of this paper is divided into five different sections. In section 2, mathematical formulation of STATCOM is discussed. Proposed algorithm for operation of STATCOM with BESS at point of common coupling (PCC) is discussed to achieve stability margin for micro-grid in section 3. Section 4 explains about single line diagram and results of the early stated problem. Finally, concluding remarks and future direction of this work has been discussed in section 5 .

\section{Mathematical Formulaiton}

For maximum power harvesting from the wind, a mathe- matical model of the wind turbine is presented. All essential parameters have been calculated by precisely considering wind speed, the angular speed of turbine blades, maximum allowed angle of rotor blades, temperature and pressure of wind, and other limiting constraints. After that control scheme of STATCOM for transient voltage stability and intelligent reactive and active power dispatch is discussed.

\subsection{Mathematical Modelling of Wind Turbine}

The mechanical power that turbine units extract from wind is given in eq (1)

$$
P_{w}=\frac{1}{2} A \rho u_{w}\left(u_{u}^{2}-u_{d}^{2}\right)
$$

where ' $u$ ' ' is the velocity of upstream wind at the point where

it enters the rotor blades and ' $u d$ ' is velocity of downstream wind at the exit of rotor blades. Using mass flow ${ }^{27}$ rate, we can write (1) as (2),

$$
A \rho u_{w}=\frac{A \rho\left(u_{u}-u_{d}\right)}{2}
$$

where ' $u_{w}$ ' is the mean of velocity at the entrance and exit of blades. From the manipulation of eq (1) we will get (3),

$$
\begin{gathered}
P_{w}=\frac{A \rho\left(u_{u}^{2}-u_{d}^{2}\right)}{2} \frac{\left(u_{u}+u_{d}\right)}{2} \\
\left.P_{w}=\frac{1}{2}\left[A \rho\left\{\frac{u_{u}}{2}\left(u_{u}^{2}-u_{d}^{2}\right)\right)+\frac{u_{d}}{2}\left(u_{u}^{2}-u_{d}^{2}\right)\right\}\right] \\
P_{w}=\left[A \rho u_{u}^{3}\left\{\frac{1+\frac{u_{d}}{u_{u}}-\left(\frac{u_{d}}{u_{u}}\right)^{2}-\left(\frac{u_{d}}{u_{u}}\right)^{3}}{2}\right\}\right] \\
P_{w}=\frac{1}{2} A \rho u_{u}^{3} C_{P_{u}} \\
C_{P_{u}}=\frac{1+\frac{u_{d}}{u_{u}}-\left(\frac{u_{d}}{u_{u}}\right)^{2}-\left(\frac{u_{d}}{u_{u}}\right)^{3}}{2}
\end{gathered}
$$

In eq (4) ' $\mathrm{CPu}$ ' is the power coefficient. It basically represents the portion of up-stream wind that is harvested by blades. Moreover, the word "Rotor Efficiency" is extensively used for this. ' $\mathrm{CPu}$ ' is not a fixed value its varying value relies on the "tip speed ratio", which is the ratio of ' $\mathrm{ud}$ ' and 'uu' of turbine.

$$
\lambda=\frac{u_{d}}{u_{u}}
$$

Blade tip ratio ' $\lambda$ ' can also be found in $\mathrm{m} / \mathrm{s} 2$ from eq (6),

$$
\lambda=\frac{r \times w_{T}}{u_{w}}
$$

where $\mathrm{uw}=$ wind speed, $\mathrm{wT}=$ angular speed of the turbine,

$r=$ radius of the turbine.

From eq (4) and (5) we get (7),

$$
C_{P}=\frac{\left(1-\lambda^{2}\right)(1+\lambda)}{2}
$$

For the purpose of finding maximum value of ' $\mathrm{CP}$ ', we need to take differential of eq (7) w.r.t ' $\lambda$ ' and put the entire equation equal to zero. That yields $\lambda=-1,1 / 3$ from which only $\lambda=1 / 3$, yields maximum value of ' $\mathrm{CP}$ ' (that is $\mathrm{CP}=16 / 27$ ). According to the Betz limit wind turbine can only harvest $59.3 \%$ of the total kinetic energy from wind $(\mathrm{CPmax}=0.59)$. In spite of everything wind turbines can't operate at this limit in real world. 
Saqif Imtiaz (et al.), Micro-Grid Stability Improvement Using Static Synchronous Compensator Assisted with Battery Energy Storage System

$$
\begin{gathered}
\rho=\frac{P}{T r_{g}} \\
P=\rho r_{g} T
\end{gathered}
$$

Where ' $\mathrm{P}$ ' is pressure, ' $\mathrm{T}$ ' is temperature and ' $\mathrm{rg}$ is the gas constant. Another important factor is altitude, since the pressure and temperature greatly vary with height, which in turn affects the density of air. After considering height in analysis we get relation for STP (Standard Temperature and Pressure) in eq (10).

$$
\rho=\rho_{0} e \frac{-0.297 H}{3048}
$$

where ' $\mathrm{H}$ ' is the elevation. $\mathrm{Eq}$ (11) rotor efficiency in terms of pitch angle and tip speed ratio as suggested by Bose and Anderson [29] is

$$
\begin{aligned}
& C_{P} \\
& =\frac{\left(\lambda-5.6-0.022 \theta^{2}\right) e^{-0.17 \lambda}}{2}
\end{aligned}
$$

where ' $\lambda$ ' is the turbine tip speed ratio given by $\lambda=u w / w t \quad$, uw is wind speed in mph and wt is angular turbine speed in rads-1and ' $\theta$ ' is pitch angle of blades. Parameters of turbine units are given in Table I. Operating characteristics of wind turbine is shown in Fig 1.

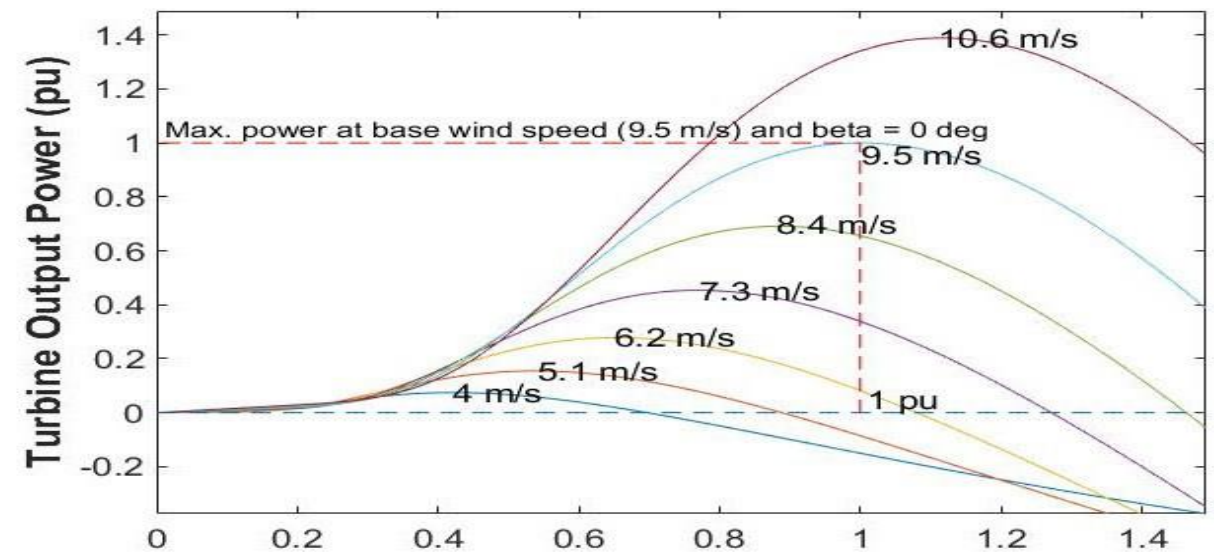

Fig. 1: Operating Characteristics of wind turbine.

Table I: Parameters of wind turbine units in $\mathrm{MG}^{2}$

\begin{tabular}{|c|c|}
\hline Parameters & Values \\
\hline $\begin{array}{c}\text { Induction } \\
\text { generator class }\end{array}$ & 6-pole squirrel cage \\
\hline $\begin{array}{c}\text { Inductance } \\
\text { (rotor, stator) }\end{array}$ & $\begin{array}{r}L r=0.1796 \mathrm{H}, \\
L s=0.1252 \mathrm{H}\end{array}$ \\
\hline $\begin{array}{c}\text { Frequency, } \\
\text { Rating, Voltage }\end{array}$ & $\begin{array}{c}\mathrm{f}=60 \mathrm{~Hz}, \mathrm{P}=3 \mathrm{MW} \times 2 \\
\text { units, V=600 }\end{array}$ \\
\hline $\begin{array}{c}\text { Friction factor } \\
\text { Resistance } \\
\text { (stator and rotor) }\end{array}$ & $\begin{array}{c}R s=0.0485 \Omega, R r \\
=0.0438 \Omega\end{array}$ \\
\hline $\begin{array}{c}\text { Rated wind } \\
\text { speed for IGs }\end{array}$ & $9 \mathrm{~m} / \mathrm{s}$ \\
\hline Pitch angle & $\theta_{\max }=50$ degree \\
\hline
\end{tabular}

\subsection{STATCOM Control Scheme}

STATCOM is working in coordination with energy storage system, in such a way that rapid and consistent support of both reactive and active power is provided for stabilization of voltage profile at point of common coupling (PCC). For this purpose, the control strategy opted by the statcom is to somehow maintain the terminal voltages (VPCC). For this reason, the voltage is perceived at the PCC and is compared with the $\mathrm{Vr}$ (reference voltage). The error between these two voltages $(\mathrm{Ve})$ is handled by controller. Output 
Saqif Imtiaz (et al.), Micro-Grid Stability Improvement Using Static Synchronous Compensator Assisted with Battery Energy Storage System

(pp. $59-72)$

from the controller (Imq ) governs the amount of amplitude of source current (reactive power component) to be generated by the statcom. The $\mathrm{d}-\mathrm{q}$ axis model in stationary reference frame is used for the simplification of 3-phase calculations.

The source voltages have two components direct/in-phase and quadrature. Direct unit vectors are vx, vy \& vz are 3-phase sinusoidal functions, which are obtained from dividing the $\mathrm{Va}, \mathrm{Vb} \& \mathrm{Vc}$ (terminal AC voltages) by their amplitude Vm. Quadrature unit vectors ux, uy \& uz of these voltages are acquired from the in-phase vectors vx, vy \& vz respectively. In order to regulate the statcom terminal voltages the amplitude of voltage $\mathrm{Vm}$ is calculated from the instantaneous PCC voltages $(\mathrm{Va}, \mathrm{Vb} \& \mathrm{Vc})$. The voltage error signal is then generated by comparing $\mathrm{Vm}$ and $\mathrm{Vr}$. Upon multiplication of quadrature unit vectors ux, uy \& uz with the output from controller Imq we get quadrature component of source currents ixq, iyq \& izq. The dc voltages Vdc of the super capacitor is detected and matched with reference dc voltages Vdcr as a consequence of which Vdce error voltage is generated. Which is treated by another controller, output from which is Imd. This Imd controls the amplitude of the active component of statcom current. From the multiplication of this controller output Imd with in-phase unit vectors vx, vy \& vz, inphase components of the source current ixd, iyd \& izd are obtained. The summation of inphase ixd, iyd, izd and quadrature ixq, iyq, izq current components yields the reference source currents ixqr, iyqr \& izqr. That is compared with measured source current ix, iy , iz from PCC in a PWM (Pulse Width Modulation) current controller to produce the switching signals for the Voltage Source Converter (VSC) in statcom. The VSC in turn produces the reactive current in response which is either fed into the system or either absorbed from the system.
The voltages at the PCC are $\mathrm{Va}, \mathrm{Vb} \& \mathrm{Vc}$ which are sensed, their amplitude is obtained from eq (12).

$$
V_{m}=\sqrt{\frac{2}{3}\left(V_{a}^{2}+V_{b}^{2}+V_{c}^{2}\right)}
$$

Eq (13) provides In-phase unit vectors.

$$
v_{x}=\frac{V_{a}}{V_{m}}, v_{y}=\frac{V_{b}}{V_{m}}, v_{z}=\frac{V_{c}}{V_{m}}
$$

The quadrature unit vectors ux, uy, uz are derived from in-phase unit vectors vx, vy, vz are given in eq (14).

$$
\begin{aligned}
& u_{x}=\frac{v_{z}}{\sqrt{(3)}}-\frac{v_{y}}{\sqrt{(3)}} \\
& u_{y}=\frac{v_{x} \sqrt{3}}{2}+\frac{\left(v_{y}-v_{z}\right)}{2 \sqrt{3}} \\
& u_{z}=-\frac{v_{x} \sqrt{3}}{2}+\frac{\left(v_{y}-v_{z}\right)}{2 \sqrt{3}}
\end{aligned}
$$

Reference current of the statcom actually has two parts in-phase \& quadrature component. Their values are computed as follows. From the 'Ve' voltage error between the ' $\mathrm{Vm}$ ' measured voltage (3-phase voltages from to $\mathrm{PCC}$ ) and the ' $\mathrm{Vr}$ ' reference voltage, quadrature component of the reference current is obtained. 'Ve' at nth instant is provided in eq (15).

$$
V_{e(n)}=V_{r}-V_{m(n)}
$$

Eq (16) shows the output of the controller at nth sampling instant

$$
\begin{aligned}
I_{m q(n)}=I_{m q(n-1)} & +K_{i} V_{e(n)} \\
& +K_{p}\left\{V_{e(n)}-V_{e(n-1)}\right\}
\end{aligned}
$$

where ' $\mathrm{Ki}$ ' and ' $\mathrm{Kp}$ ' are integral \& proportional gains of the controller. ' $\mathrm{Ve}(\mathrm{n})$ ' and ' $\mathrm{Ve}(\mathrm{n}-1)$ ' are errors in voltages at $\mathrm{nth}$ and (n-1)th instant. ' $\operatorname{Imq}(\mathrm{n}-1)$ ' is the amplitude of the quadrature component of source current at (n-1)th instant. The quadrature component of the reference current is presented in eq (17).

$$
i_{x q}=I_{m q} u_{x}, i_{y q}=I_{m q} u_{y}, i_{z q}=I_{m q} u_{z}
$$


Saqif Imtiaz (et al.), Micro-Grid Stability Improvement Using Static Synchronous Compensator Assisted with Battery Energy Storage System

For in-phase component of the reference current the error voltage at the dc-capacitor is provided in eq (18).

$$
V_{d c e(n)}=V_{d c r}-V_{d c(n)}
$$

where 'Vdcr' is the dc reference voltage that is fixed and ' $\mathrm{Vdc}(\mathrm{n})$ ' is the voltage that is measured across the super capacitor of statcom. Eq (19) presents the output of the controller for controlling the dc bus voltages at nth sampling instant.

$$
\begin{aligned}
I_{\operatorname{md}(n)}=I_{\operatorname{md}(n-1)} & +K_{i} V_{\mathrm{dce}(n)} \\
& +K_{p}\left\{V_{\mathrm{dee}(n)}\right. \\
& \left.-V_{\mathrm{dce}(n-1)}\right\}
\end{aligned}
$$

'Imd' is the active power component of source current. 'Ki' \& 'Kp' are the integral and proportional gains of the controller respectively. In-phase reference current components are estimated in eq (20).

$i_{x d}=I_{m d} v_{x}, i_{y d}=I_{m d} v_{y}, i_{z d}=I_{m d} v_{z}$

Total reference current is given in eq (21) that goes to the PWM current controller is the sum of both quadrature \& in-phase components.

$$
\begin{aligned}
i_{x}=i_{x d}+i_{x q}, i_{y} & =i_{y d}+i_{y q}, i_{z} \\
& =i_{z d}+i_{z q}
\end{aligned}
$$

Now at PWM current controller the reference source currents and sensed source currents (from PCC) are compared. The output of which decides the switching pattern of IGBTs, by modifying the gate drive signals of IGBT. Eq (22) provides source error currents.

$$
\begin{aligned}
i_{\text {sxe }}=i_{x}-I_{a}, i_{\text {sye }} & =i_{y}-I_{b}, i_{\text {sze }} \\
& =i_{z}-I_{c}
\end{aligned}
$$

Output of VSC produces reactive current in response which is fed into the system and absorbed from the system in case of excess reactive power on PCC. Reactive power flow between statcom and PCC is given by eq. (23). where Vpcc is PCC voltages, Vstat is terminal voltages of statcom, $\mathrm{X}$ is total reactance due to interconnection equipment, $\varphi$ is phase difference between Vpcc and Vstat.

$Q=V_{p c c} \frac{V_{p c c}-V_{s t a t} \cos \phi}{X}$

DC side of statcom is coordinated with energy storage system so STATCOM also compensates for minor active power deficiencies. A power system that is supposed to drive the domestic, industrial and commercial loads is always designed to support the unsymmetrical as well as Nonlinear loads. Because the non-linear load will cause harmonics in the system, which will eventually degrade the voltages at bus bar. And due to unbalanced load unequal currents flow through 3-phases. Statcom is capable of filtering such harmonics \& balancing the unsymmetrical loads [30].

\section{The Proposed Algorithm}

Joint strategy of STATCOM with battery bank charging for the stability improvement of micro-grid is shown in Fig. 2

Step 1: Evaluation of voltage variations at point of integration bus (Vpcc) are initialed and there are three possible outcomes for Vpcc are obtained.

Step 2: If Vpcc variations are lie within defined limits, then Vpcc will equal to reference voltage (Vref) and hence power delivered to the load.

Step 3: As per the conditions of voltage deviations, if Vpcc is less than (Vref) reveals that micro-grid (MG) has voltage instability concerns at pint of common coupling (PCC) bus. MG suffering under voltage at condition at PCC bus. In order to ensure voltage stability STATCOM used DC side battery bank provide instant support of reactive and active power support. If battery bank charging level is low STATCOM control managed to charge it through power grid and also used utility grid for backup power reserve for voltage stability. 


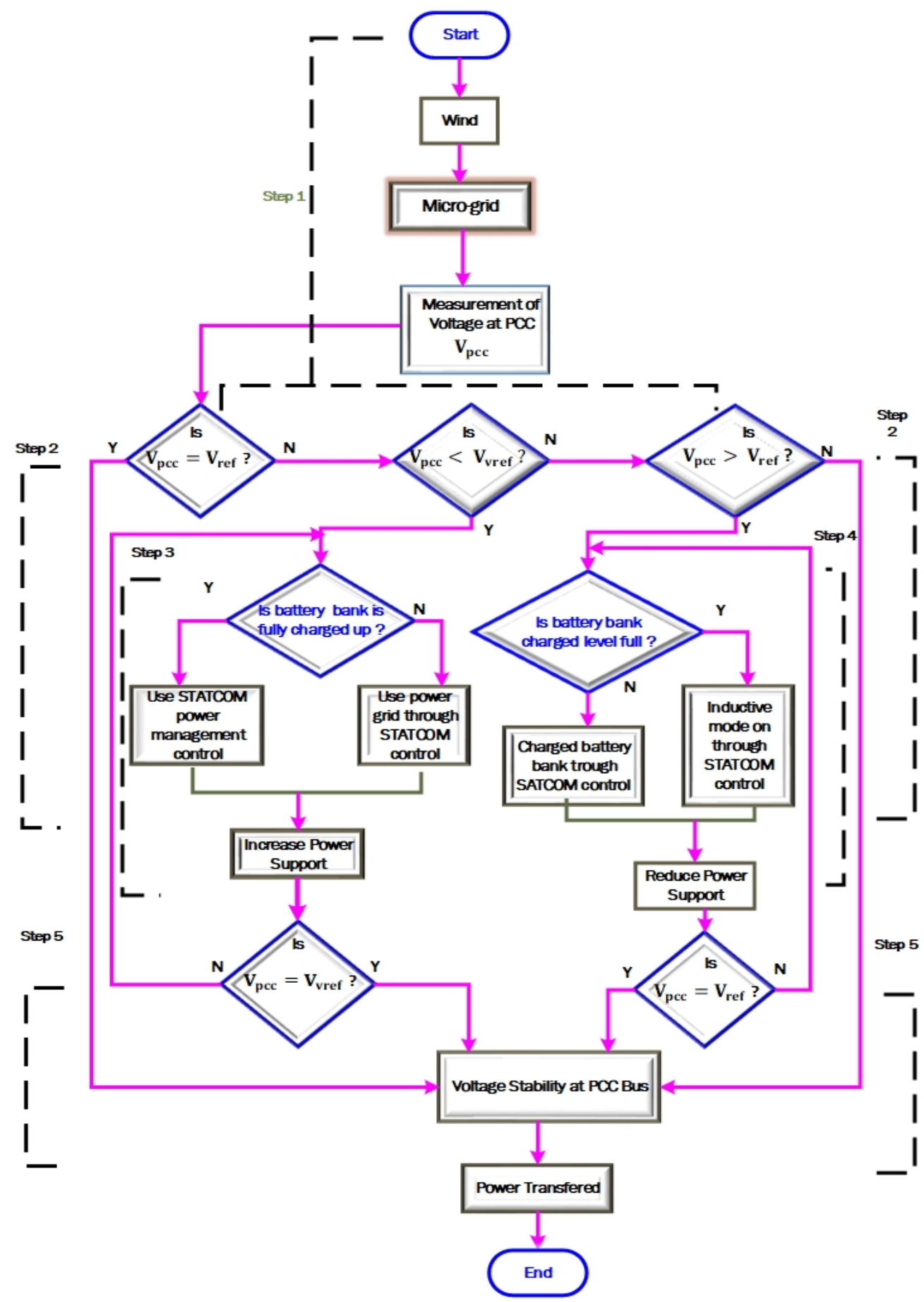

Fig. 2: Proposed joint strategy of STATCOM with battery energy storage system (BESS) for stability improvement of micro-grid 
Saqif Imtiaz (et al.), Micro-Grid Stability Improvement Using Static Synchronous Compensator Assisted with Battery Energy Storage System

(pp. $59-72$ )

Step 4: As per the conditions of voltage deviations, if Vpcc is greater than (Vref) reveals that micro-grid (MG) has voltage instability concerns at pint of common coupling (PCC) bus. MG suffering over voltage condition at PCC bus which is mostly unlikely event. In order to ensure voltage stability STATCOM control used its inductive mode of switches in order to absorb excessive available reactive power and hence reduce reactive power in MG system. If battery bank charging level is low STATCOM control managed to charge it through power grid and also used utility grid for backup power reserve for voltage stability.

Table II: Buses and loads input parameters for micro-grid ${ }^{2}$

\begin{tabular}{|l|l|l|}
\hline Buses & Voltage & Load \\
\hline B1 & 69 & - \\
\hline B2 & 69 & - \\
\hline B3 & 13.8 & - \\
\hline B4 & 13.8 & - \\
\hline B5 & 13.8 & - \\
\hline B6 & 13.8 & - \\
\hline B7 & 0.48 & 6000 \\
\hline B8 & 0.48 & 6000 \\
\hline B9 & 13.8 & - \\
\hline B10 & 13.8 & - \\
\hline B11 & 0.48 & 1802.8 \\
\hline B12 & 0.48 & 3000 \\
\hline B13 & 0.6 & - \\
\hline B14 & 13.8 & - \\
\hline B15 & 0.48 & 1500 \\
\hline B16 & 13.8 & - \\
\hline B17 & 0.48 & 1400 \\
\hline PCC & 13.8 & - \\
\hline Sten & & \\
\hline
\end{tabular}

Step 5: When the voltage at PCC bus close to its defined reference value, then power will be delivered reliably.

\section{Simulation Results and Discussion}

A single line diagram of micro-grid distributed generation system is shown in Fig. 3. Wind power-assisted distributed generators in microgrid has induction generators that are unable to provide instant reactive power support toward regular load intermittencies. Wind turbine units have a total rating of $6 \mathrm{MW}$ and a diesel generator rating of $4 \mathrm{MW}$. Intermittencies of load variations at microgrid causes voltage instability at PCC. So, the interconnection of micro-grid and conventional grid becomes weak and power restoring of micro-grid for stable power generation becomes major challenge. Table 2 shows bus names, nominal voltage of buses and rating of loads attached to corresponding buses. Load variation at PCC are between 8 MVA to 15 MVA3,4.

In this article, the proposed STATCOM assisted battery energy storage system scheme is developed, which is integrated at PCC as shown in Fig. 3. Fig. 4, shows high intermittencies of inductive load variations at the PCC of the micro-grid distribution system. During these events of load variations microgrid control system is unable to provide support for the MG to restore power stability for stable power generation. In Fig. 4, at 1.5s to $1.68 \mathrm{~s} \mathrm{MG}$ is struggling to regain power stability and continues to smooth power generation, but at $1.9 \mathrm{~s}$ MG completely lost power stability and shuts down. In Fig. 5, regardless of heavy inductive load switching on feeders at $1.5 \mathrm{~s}$ to $1.68 \mathrm{~s}$, MG survives to restore power stability and, continues smooth power delivery, due to the newly incorporated developed scheme at the MG distribution system. 
Saqif Imtiaz (et al.), Micro-Grid Stability Improvement Using Static Synchronous Compensator Assisted with Battery Energy Storage System

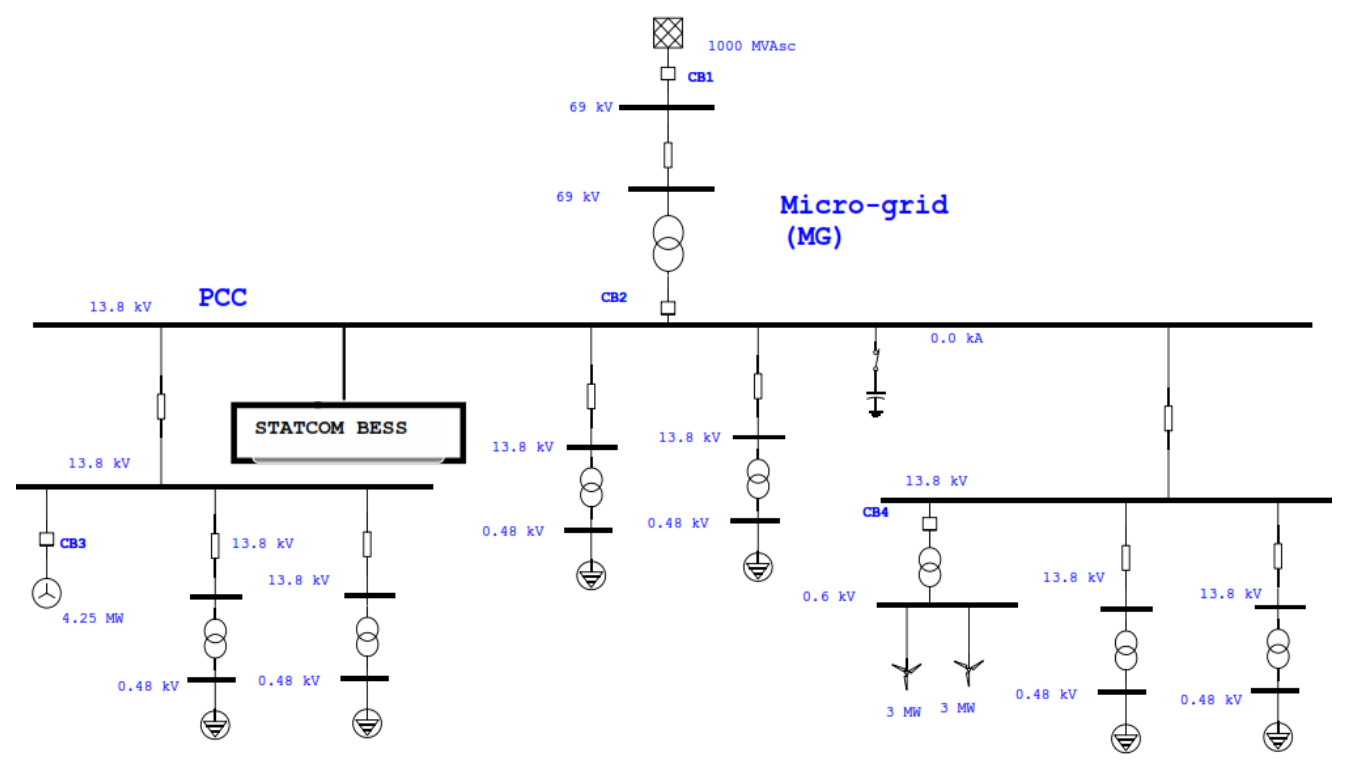

Fig. 3: Single line diagram of microgrid.

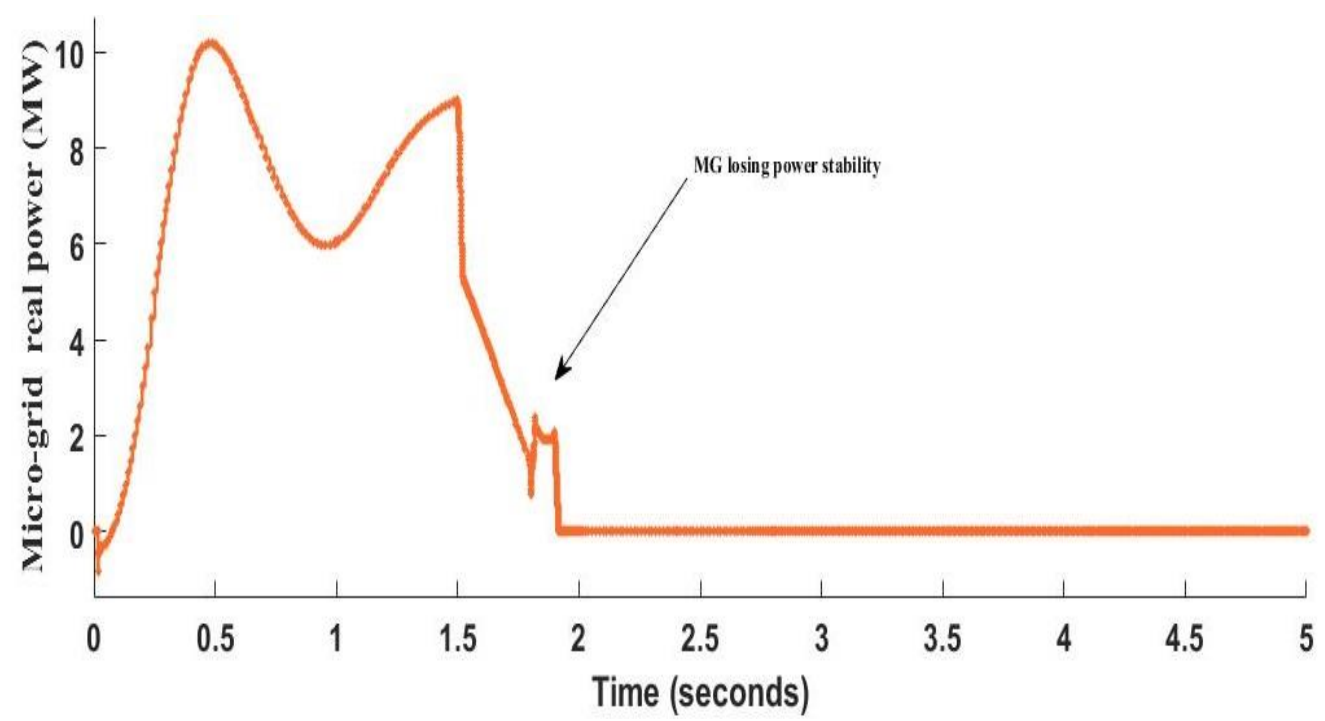

Fig. 4: Micro-grid (MG) lost to restore power stability without STATCOM assisted battery energy storage system (BESS) 


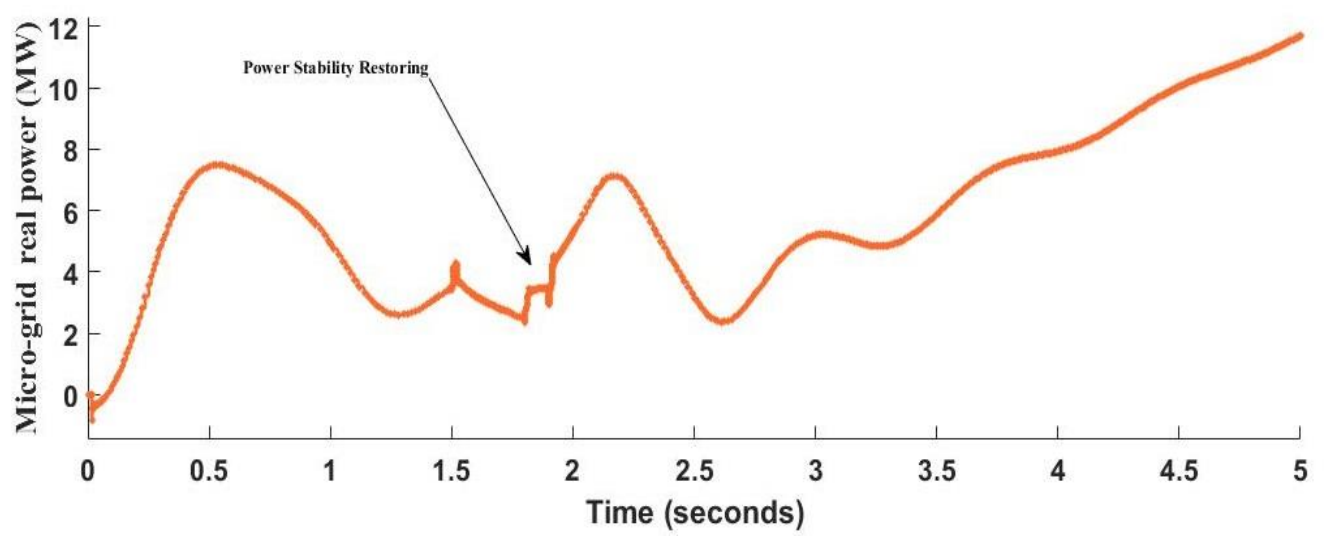

Fig. 5: Micro-grid (MG) restore power stability with STATCOM assisted battery energy storage system ( BESS).

In Fig. 6, due to heavy inductive load switching at the micro-grid distribution system, voltage stability at PCC bus greatly affected and major voltage stability concerns can be seen. In Fig. 6, at $1.5 \mathrm{~s}$ to $1.68 \mathrm{~s}$ undervoltage instability is more prominent. But with the use of STATCOM assisted with BESS developed scheme in MG, it is seen at $1.5 \mathrm{~s} s$ to $1.68 \mathrm{~s}$ of voltage graph in Fig. 7. MG achieved voltage stability margin affectively.
Micro-grid restores power stability and voltage stability by the utilization of new developed STATCOM assisted with battery energy storage system (BSS) scheme. This scheme manages power support for MG. Active power and reactive support maintain the MG to regain stability. In Fig. $8,1.5 \mathrm{~s}$ to $5 \mathrm{~s}$ graph show STATOCOM assisted with BESS provides instant reactive power support for micro-grid.

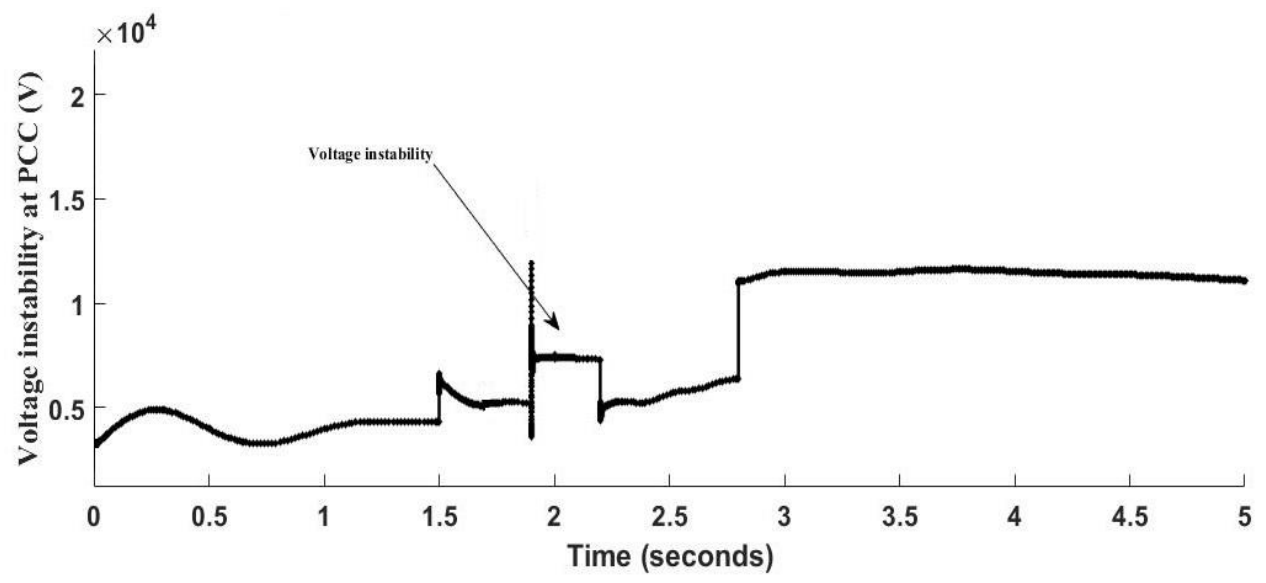

Fig. 6: Voltage instability without STATCOM assisted BEES 
Saqif Imtiaz (et al.), Micro-Grid Stability Improvement Using Static Synchronous Compensator Assisted with Battery Energy Storage System

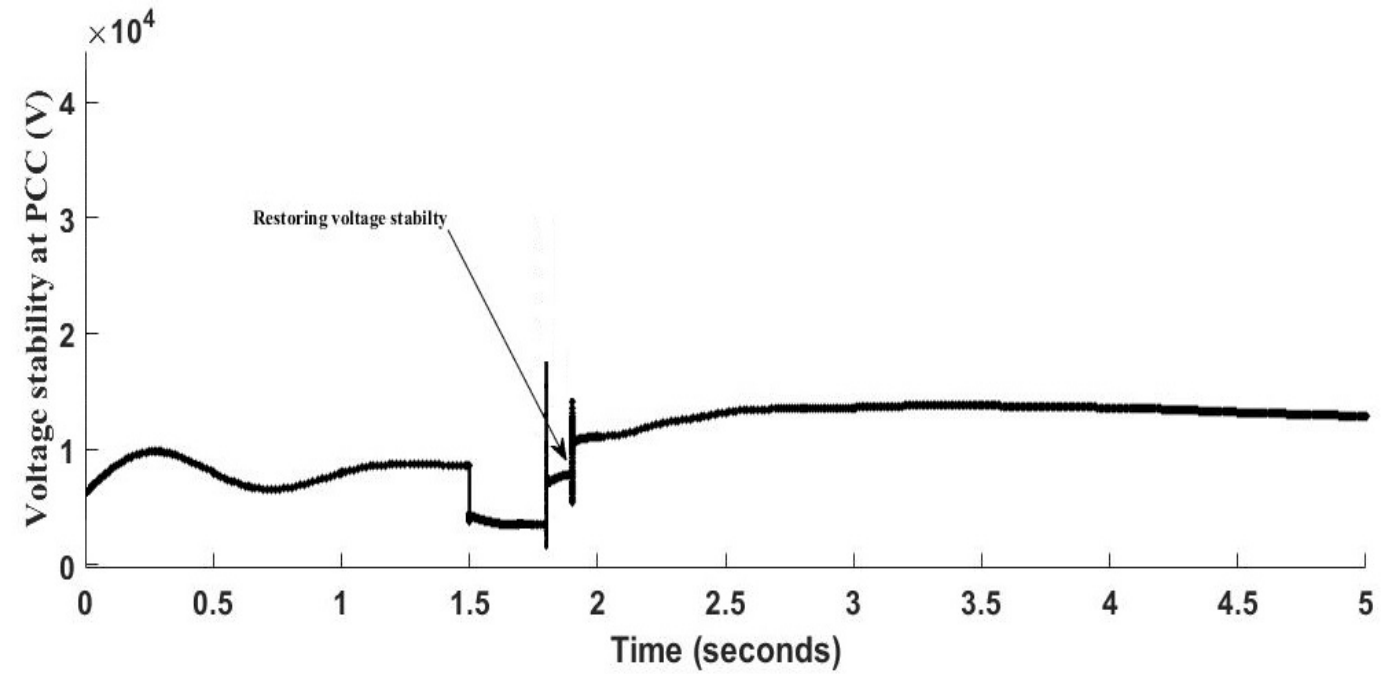

Fig 7: Voltage stability with STATCOM assisted BEES

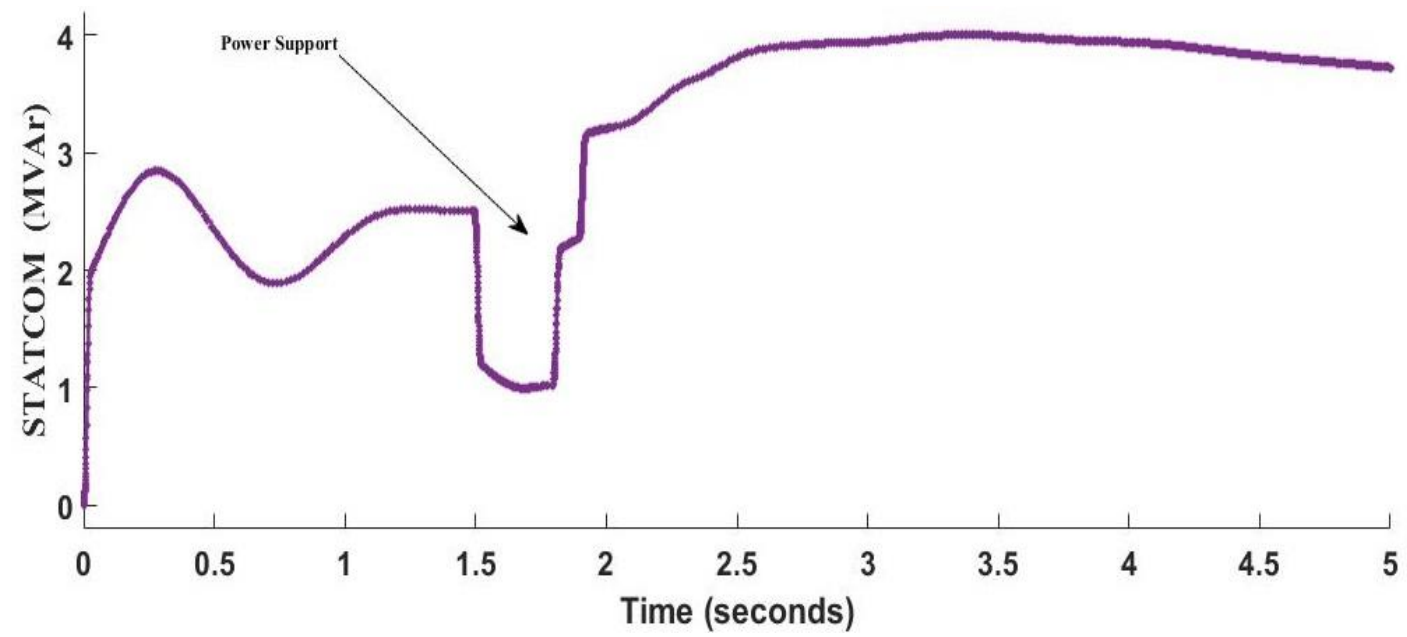

Fig 8: Power management of STATCOM assisted BEES

\section{Conclusion and Future Research}

In this article, a proposed scheme of placing STATCOM assisted with battery energy storage system (BESS) at point of common coupling (PCC), had developed for restoring power stability and improving voltage stability at PCC of wind-assisted micro-grid coupled with the power grid. High intermittencies of load variation at PCC of the micro-grid (MG), was a major concern, as it causes problems of voltage instability and restoring stable power in integrated microgrid. Placed STATCOM assisted battery energy storage system (BESS) at PCC manages real and reactive power support during intermittencies of load variation to sort out voltage stability and power restoring concerns of MG. Furthermore, in the future, the placement of a unified power flow controller (UPFC) can be used to improve the 
Saqif Imtiaz (et al.), Micro-Grid Stability Improvement Using Static Synchronous Compensator Assisted with Battery Energy Storage System

stability issues of the micro-grid integrated power grid.

\section{References}

[1] A. B. Rao and E. S. Rubin, "A technical, economic, and environmental assessment of amine-based co2 capture technology, for power plant greenhouse gas control," Environmental science \& technology, vol. 36, no. 20, pp. 4467-4475, 2002.

[2] N. Panwar, S. Kaushik, and S. Kothari, "Role of renewable energy sources in environmental protection: a review," Renewable and Sustain- able Energy Reviews, vol. 15, no. 3, pp. 1513-1524, 2011.

[3] A. Zervos, C. Lins, and J. Muth, REthinking 2050: a 100\% renewable energy vision for the European Union. EREC, 2010.

[4] A. A. Bayod-Ru'jula, "Future development of the electricity systems with distributed generation," Energy, vol. 34, no. 3, pp. 377-383, 2009.

[5] J. P. Lopes, N. Hatziargyriou, J. Mutale, P. Djapic, and N. Jenkins, "In- tegrating distributed generation into electric power systems: A review of drivers, challenges and opportunities," Electric power systems research, vol. 77, no. 9, pp. 1189-1203, 2007.

[6] C. Wang, J. Yan, C. Marnay, N. Djilali, E. Dahlquist, J. Wu, and H. Jia, "Distributed energy and microgrids (dem)," 2018.

[7] P. Basak, S. Chowdhury, S. H. nee Dey, and S. Chowdhury, "A literature review on integration of distributed energy resources in the perspective of control, protection and stability of microgrid," Renewable and Sustainable Energy Reviews, vol. 16, no. 8, pp. 5545-5556, 2012.

[8] B. Tamimi and C. A. Can izares, "Modeling and application of hybrid power flow controller in distribution systems," IEEE Transactions on Power Delivery, vol. 33, no. 6, pp. 2673-2682, 2018.

[9] T. Manglani and Y. Shishodia, "Voltage profile improvement in radial distribution system using plant growth simulation algorithm."

[10] S. Jalilzadeh and S. Golchin, "Voltage flicker parameters estimation usingshuffled frog leaping algorithm

(pp. 59-72)

(sfla) andimperialistic competitive algorithm (ica)," INTERNATIONAL JOURNAL OF COMPUTERS \& TECHNOLOGY, vol. 15, no. 1, pp. 63736378, 2016.

[11] E. O. Hasan, A. Y.Hatata, E. A. Badran, and F. M. Yossef, "Optimal coordination of voltage control devices in distribution systems connected to distributed generations," Electrical Engineering, vol. 101, no. 1, pp. 175-187, 2019.

[12] K. C. Sharma, S. Sinha, and S. R. Somanshu, "Minimization of power loss in distribution system using svc and statcom," 2017.

[13] H. Suyono, R. N. Hasanah, and E. P. Widyananda, "Power system optimization of static var compensator using novel global harmony search method," in Accepted to be published in the International Journal of Electrical and Electronic Engineering \& Telecommunications(IJEETC), 2019.

[14] S. H. Kiran, S. S. Dash, and C. Subramani, "Performance of two modified optimization techniques for power system voltage stability problems," Alexandria Engineering Journal, vol. 55 , no. 3, pp. 2525-2530, 2016.

[15] H. Saikumar et al., "Voltage stability enhancement in radial distribution system by shunt capacitor and statcom," in Emerging Research in Electronics, Computer Science and Technology. Springer, 2019, pp. 1455-1468.

[16] R. Sirjani and A. R. Jordehi, "Optimal placement and sizing of distri- bution static compensator (d-statcom) in electric distribution networks: A review," Renewable and Sustainable Energy Reviews, vol. 77, pp. 688-694, 2017.

[17] M. Y.Pathak and J. Jamnani, "Design and hardware implementation of svc using thyristorised control for improving power factor and voltage profile of inductive loads," in 2016 IEEE 6th International Conference on Power Systems (ICPS). IEEE, 2016, pp. 1-6.

[18] A. Rath, S. R. Ghatak, and P. Goyal, "Optimal allocation of distributed generation (dgs) and static var compensator (svc) in a power system, using revamp voltage stability indicator," in 2016 National Power Systems Conference (NPSC). IEEE, 2016, pp. 1-6.

[19] V. Asgharian and V. I. Genc, "Multiobjective optimization for voltage 
Saqif Imtiaz (et al.), Micro-Grid Stability Improvement Using Static Synchronous Compensator Assisted with Battery Energy Storage System (pp. 59 - 72)

regulation in distribution systems with distributed generators," in 2016 IEEE Electrical Power and Energy Conference (EPEC). IEEE, 2016, pp. 1-6.

[20] S. Wang, S. Chen, L. Ge, and L. Wu, "Distributed generation hosting capacity evaluation for distribution systems considering the robust optimal operation of oltc and svc," IEEE Transactions on Sustainable Energy, vol. 7, no. 3, pp. 1111-1123, 2016.

[21] X. Xu, Z. Xu, X. Lyu, and J. Li, "Optimal svc placement for maximizing photovoltaic hosting capacity in distribution network," IFACPapersOnLine, vol. 51, no. 28, pp. 356361, 2018.

[22] Wang, Qi, Bin Wang, Wanwan Xu, and Jiapan Xu. "Research on STATCOM for reactive power flow control and voltage stability in microgrid." In 2018 13th IEEE Conference on Industrial Electronics and Applications (ICIEA), pp. 2474-2479. IEEE, 2018.

[23] A. A. A. El-Ela, R. A. El-Sehiemy, A.-M. Kinawy, and M. T. Mouwafi, "Optimal capacitor placement in distribution systems for power loss re- duction and voltage profile improvement," IET Generation, Transmission \& Distribution, vol. 10, no. 5, pp. 12091221, 2016.

[24] A. Aravinth, V. A. Vatul, K. Narayanan, K. Muthukumar, and T. Senjyu, "A multiobjective framework to improve voltage stability in a distribution network," International Journal of Emerging Electric Power Systems, vol. 20, no. 1, 2019.

[25] Bakir, Hale, and Ahmet Afsin Kulaksiz. "Modelling and voltage control of the solar-wind hybrid micro-grid with
Optimized STATCOM using GA and

BFA." Engineering Science and Technology, an International Journal 23, no. 3 (2020): 576-584.

[26] Qi, Jun, Wenbin Zhao, and Xiaoyan Bian. "Comparative Study of SVC and STATCOM Reactive Power Compensation for Prosumer Microgrids with DFIG-based Wind Farm integration." IEEE Access (2020).

[27] H. Mehrjerdi, "Simultaneous load leveling and voltage profile improvement in distribution networks by optimal battery storage planning," Energy, 2019.

[28] S. Imtiaz, M. W. Altaf, A. Riaz, M N. Naz, M. K. Bhatti, and R. G. Hassan, "Intermittent wind energy assisted micro-grid stability enhancement using security index currents," in 2019 15th International Conference on Emerging Technologies (ICET). IEEE, 2019, pp. 1-6.

[29] A. W. Manyonge, R. Ochieng, F. Onyango, and J. Shichikha, "Mathematical modelling of wind turbine in a wind energy conversion system: Power coefficient analysis," Applied Mathematical Sciences, vol. 6, no. 91, pp. 4527-4536, 2012.

[30] Ul-Haq, Azhar, Zubair Yamin, Saifullah Awan, and Almas Ajum. "Frequency Control of SEIG Based Microgrid during Transition from Grid Connected to Island Mode." In 2020 9th International Conference on Industrial Technology and Management (ICITM), pp. 234-238. IEEE, 2020. 